\title{
Characterization of Genomic Microsatellite Markers and Analysis of Pollen Donors Number for Single Cone of Chinese fir
}

Li Kuipeng ${ }^{1}$, Chen Shichang ${ }^{1}$, Dong Leiming ${ }^{2}$, Liang Ji ${ }^{3}$, Chen Daixi ${ }^{1}$, Huang Kaiyong ${ }^{1} \square$

1 Guangxi Forestry Research Institute, Key Laboratory of Central South Fast-growing Timber Cultivation of Forestry Ministry of China/Guangxi Key

Laboratory of Superior Timber Trees Resource Cultivation, Nanning, 530002, China

2 Chinese Academy of Forestry, Research Institute of Forestry, Beijing, 100091, China

3 Guangxi University, Forestry College, Nanning, 530004, China

$\triangle$ Corresponding author email: huangky73@163.com

Tree Genetics and Molecular Breeding, 2020, Vol.10, No.5 doi: $\underline{10.5376 / \operatorname{tgmb} .2020 .10 .0005}$

Received: 29 May, 2020

Accepted: 12 Aug., 2020

Published: 14 Aug., 2020

Copyright $\odot 2020 \mathrm{Li}$ et al., This is an open access article published under the terms of the Creative Commons Attribution License, which permits unrestricted use, distribution, and reproduction in any medium, provided the original work is properly cited.

Preferred citation for this article:

Li K.P., Chen S.C., Dong L.M., Liang J., Chen D.X., and Huang K.Y., 2020, Characterization of genomic microsatellite markers and analysis of pollen donors number for single cone of Chinese fir, Tree Genetics and Molecular Breeding, 10(5): 1-7 (doi: 10.5376/tgmb.2020.10.0005)

\begin{abstract}
Chinese fir [Cunninghamia lanceolate (Lamb.) Hook] is one of the most important indigenous timber tree species in China. The aim of the present work is to characterize simple sequence repeat (SSR) loci derived from the specific length amplified fragment sequencing (SLAF) data of the genome and to investigate the number of pollen donors for per cone was with novel SSR markers of low-frequency null alleles. A total of 58855 SLAF-SSR with frequency of 42.04 SSR/Mbp were identified in about $1.40 \mathrm{~Gb}$ Chinese fir genome. Dinucleotide repeat SSR contributed to $66.4 \%$ of the total SSR from SLAF data. The AT/AT and ATG/CAT motifs were predominant in the category of din- and trinucleotide repeat SSR. Low frequencies of null alleles $(<5 \%)$ were detected at the nine novel SSR markers with average expected heterozygosity of 0.513 and polymorphism information content score of 0.508 . The number of tested progeny of a cone was from 4 to 13 . It could be 67 pollinizers for 15 cones and the average number of pollen donors per cone was 4.5. The study points out, for the first time, that there are multiple pollen donors for single cone in gymnosperm.
\end{abstract}

Keywords Chinese fir; SLAF; SSR; Null alleles; Sibship relationships

Due to the genetic characteristics of co-dominance inheritance, high reliability and wide distribution in genome, simple sequence repeats (SSR) have been one of the most widely used molecular markers (Gong et al., 2019; Karam et al., 2019; Torokeldiev et al., 2019). The rapid development of sequencing technologies has allowed genome-wide characterization of SSR to be performed (Sonah et al., 2011; Xiao et al., 2015; Wang et al., 2018).

Microsatellites are powerful tools for pedigree analysis (Dong et al., 2018; Huang et al., 2018; Zurn et al., 2018). Despite many obvious advantages of the marker, the defect exists in SSR (Selkoe et al., 2006). The presence of null alleles significantly affect the accuracy of pedigree determination (Dong et al., 2006). Loci with null allele frequencies $(>0.05)$ should be excluded from pedigree analysis (Karaket et al., 2012; Sahoo et al., 2017).

Chinese fir [Cunninghamia lanceolate (Lamb.) Hook], a gymnosperm, is one of the most important indigenous timber tree species in China for its high growth rate, good wood quality, and the versatility of its wood (Li et al., 2017). To our best knowledge, the basic characteristic of genomic SSR from Chinese fir is unknown and the research on the pollen donors number of offspring from a cone of gymnosperm has not been reported. In the present study we describe: (1) characterization of SSR derived from the specific length amplified fragment sequencing data (SLAF-SSR) of the Chinese fir genome. (2) Evaluation of the primers validity and diversity information parameters of SLAF-SSR and expressed sequence tag (EST-SSR). (3) development of SSR markers with low-frequency null alleles $(<5 \%)$. (4) analysis of the pollen donors number of a Chinese fir cone. 


\section{Results}

\subsection{SLAF-SSR survey}

A total of 58855 SLAF-SSR, frequency of which was $42.04 \mathrm{SSR} / \mathrm{Mbp}$, were identified in about $1.40 \mathrm{~Gb}$ Chinese fir genome. The number of dinucleotide repeat SSR was 3999 , contributed to $66.4 \%$ of the total SSR. This is followed by trinucleotide repeat SSR with 16,547 , accounting for $28.1 \%$ of the total. The AT/AT and ATG/CAT motifs were predominant in the category of din- and trinucleotide repeat SSR, accounting for $43.9 \%$ and $19.9 \%$ respectively (Figure 1). The number of di- and trinucleotide SLAF-SSR was declining accompanied by number increase of the motif repeat.

\subsection{Validation of SLAF-SSR and EST-SSR}

A subset of 100 markers, which were successfully designed the primer, were randomly chosen respectively from SLAF-SSR and EST-SSR of Chinese fir. 12 individuals were employed to test the amplification validation. 62 SLAF-SSR markers presented specific products, but 51 markers of them occurred stutter bands. Only 3 SLAF-SSR markers displayed specific products and no stutter bands and demonstrated to be polymorphic. All the EST-SSR markers did not present stutter bands. 86 markers displayed specific products and 13 of them demonstrated to be polymorphic. Therefore, a total of 16 novel polymorphic SSR markers, which appear specific product and no stutter band, were development.

\subsection{Assessment of genetic diversity}

Details of 16 novel polymorphic SSR markers and their variability characteristics across 48 Chinese fir individuals were summarized in Table 1 . Seventy-one alleles were identified, with an average of 4.44 observed alleles per locus, ranging from two to nine. There were twenty-one alleles in the three loci of SLAF-SSR, with an average of 7.00 , ranging from five to nine. The expected heterozygosity, ranging from 0.334 to 0.810 (average 0.566 ) was clearly higher than the observed heterozygosity, ranging from 0.283 to 0.727 (average $0.499)$, which was in accordance with the mean fixation index ( $\mathrm{FIS}=0.103 ; \mathrm{P}<0.05$ ) and indicated there were a greater excess of homozygotes most often a result of inbreeding (Frankham et al. 2010). As a measurement of the genetic diversity, the PIC mean polymorphism level of the loci was 0.512. Eight loci were at HWE and other eight loci showed significant departure from HWE (P-value $<0.05)$. Low null allele frequencies were showed at the nine loci (F-Null<0.05), which were SSR4, SSR5, SSR6, SSR7, SSR8, SSR9, SSR11, SSR12, SSR16, with average expected heterozygosity of 0.513 and PIC score of 0.508 .

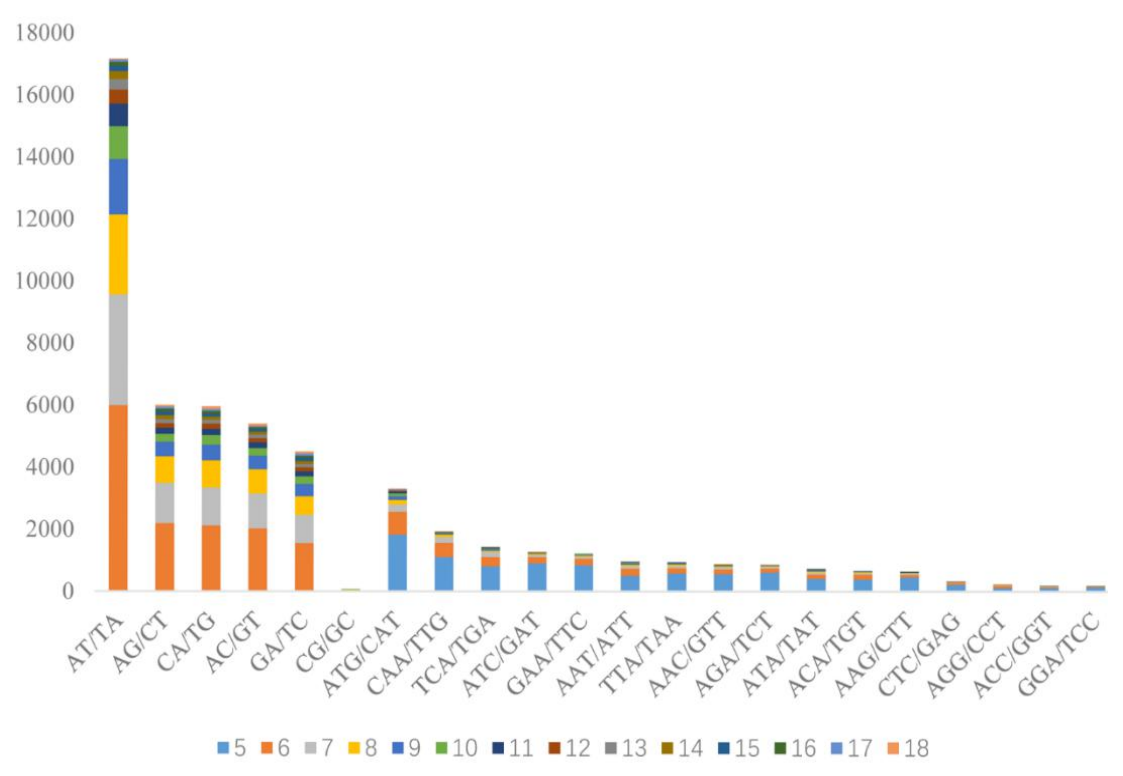

Figure 1 Distribution of di- and trinucleotide motifs SLAF-SSR of Chinese fir Note: types of tri-nucleotide motif less than $0.01 \%$ of that were not showed in this figure 
Tree Genetics and Molecular Breeding 2020, Vol.10, No.5, 1-7

http://genbreedpublisher.com/index.php/tgmb

Table 1 Characteristics of primer sequence and diversity information parameters of 16 SSR loci

\begin{tabular}{|c|c|c|c|c|c|c|c|c|c|c|c|c|}
\hline Locus & Source & Primer sequences $\left(5^{`}-3^{\prime}\right)$ & size & Repeat & $N_{\mathrm{A}}$ & $N_{\mathrm{E}}$ & $H_{\mathrm{O}}$ & $H_{\mathrm{E}}$ & $F$ is & $P I C$ & $P$-valu & $F$-Null \\
\hline SSR1 & SLAF & $\begin{array}{l}\text { R:CAAATCAGACTATG } \\
\text { F:TAAAGGTGTAATGC }\end{array}$ & 117 & $(\mathrm{AT}) 7$ & 9.00 & 5.26 & 0.283 & 0.810 & 0.114 & 0.788 & 0.002 & 0.058 \\
\hline SSR2 & SLAF & $\begin{array}{l}\text { R:TCGCATGCATGTAT } \\
\text { F:GCATCATCATCATC }\end{array}$ & 278 & $\begin{array}{l}(\mathrm{TGA}) 1 \\
2\end{array}$ & 7.00 & 4.00 & 0.604 & 0.750 & 0.472 & 0.712 & 0.000 & 0.304 \\
\hline SSR3 & SLAF & $\begin{array}{l}\text { R:GAGGGAGGAAGAG } \\
\text { F:TAGGATGGGTGGTT }\end{array}$ & 246 & (TA) 8 & 5.00 & 3.51 & 0.396 & 0.715 & 0.155 & 0.672 & 0.015 & 0.093 \\
\hline SSR4 & EST & $\begin{array}{l}\text { R:GGGTTTGGGCCCTT } \\
\text { F:TGGATGGGATTATG }\end{array}$ & 205 & $(\mathrm{AG}) 8$ & 2.00 & 1.76 & 0.558 & 0.431 & -0.026 & 0.338 & 0.927 & -0.013 \\
\hline SSR5 & EST & $\begin{array}{l}\text { R:GCGCGCGCACATAT } \\
\text { F:TTCACCTTGGCCAA }\end{array}$ & 100 & $(\mathrm{CA}) 6$ & 3.00 & 2.87 & 0.362 & 0.652 & 0.021 & 0.578 & 0.580 & 0.015 \\
\hline SSR6 & EST & $\begin{array}{l}\text { R:GGCAATCTAGCGAG } \\
\text { F:CTTGCTCTCCCTGTA }\end{array}$ & 124 & $\begin{array}{l}\text { (AATG } \\
) 5\end{array}$ & 3.00 & 2.42 & 0.457 & 0.586 & 0.073 & 0.521 & 0.733 & 0.032 \\
\hline SSR7 & EST & $\begin{array}{l}\text { R:GCATTGAGAGCGGG } \\
\text { F:AAGAAGCGTGCAGG }\end{array}$ & 233 & $\begin{array}{l}(\mathrm{CTTT}) \\
5\end{array}$ & 3.00 & 1.50 & 0.614 & 0.334 & -0.158 & 0.291 & 0.379 & -0.042 \\
\hline SSR8 & EST & $\begin{array}{l}\text { R:CTCCCCTGCCACTG } \\
\text { F:TCATGTAAGCGCGT }\end{array}$ & 260 & $(\mathrm{GGC}) 5$ & 7.00 & 4.68 & 0.296 & 0.786 & 0.104 & 0.760 & 0.014 & 0.045 \\
\hline SSR9 & EST & $\begin{array}{l}\text { R:AAATAGCCTCCCCC } \\
\text { F:ATGGCTGATGGAGG }\end{array}$ & 151 & $\begin{array}{l}(\mathrm{TTCT}) \\
6\end{array}$ & 5.00 & 3.27 & 0.417 & 0.694 & 0.159 & 0.638 & 0.035 & 0.038 \\
\hline SSR10 & EST & $\begin{array}{l}\text { R:GAAAGCGAAACGG } \\
\text { F:TAGCGAGATCGAAC }\end{array}$ & 193 & (TTG)5 & 3.00 & 2.03 & 0.575 & 0.507 & 0.160 & 0.428 & 0.385 & 0.099 \\
\hline SSR11 & EST & $\begin{array}{l}\text { R:GACGACAACCGAC } \\
\text { F:CGAAACGCCTTTTG }\end{array}$ & 189 & $(\mathrm{CCG}) 7$ & 4.00 & 1.83 & 0.568 & 0.452 & 0.045 & 0.415 & 0.743 & 0.025 \\
\hline SSR12 & EST & $\begin{array}{l}\text { R:GCCTTGTGCAAAGC } \\
\text { F:AGGAAACTGCACTG }\end{array}$ & 214 & $(\mathrm{GGA}) 6$ & 4.00 & 2.20 & 0.489 & 0.546 & 0.065 & 0.481 & 0.030 & 0.017 \\
\hline SSR13 & EST & $\begin{array}{l}\text { R:GCAAGAGCATCAGC } \\
\text { F:CAAAGTCAGGCATG }\end{array}$ & 224 & $(\mathrm{CAG}) 6$ & 4.00 & 1.57 & 0.727 & 0.362 & 0.246 & 0.344 & 0.048 & 0.015 \\
\hline SSR14 & EST & $\begin{array}{l}\text { R:AGGTGTCTTGACCT } \\
\text { F:TGTAGCGGTTATCG }\end{array}$ & 188 & $(\mathrm{CAG}) 5$ & 2.00 & 1.97 & 0.568 & 0.494 & 0.125 & 0.372 & 0.365 & 0.067 \\
\hline SSR15 & EST & $\begin{array}{l}\text { R:AGGTGTAGCAGATC } \\
\text { F:CCAGATCAATAGTC }\end{array}$ & 278 & $\begin{array}{l}(\mathrm{TTTG}) \\
5\end{array}$ & 2.00 & 1.57 & 0.705 & 0.363 & 0.187 & 0.297 & 0.184 & 0.103 \\
\hline SSR16 & EST & $\begin{array}{l}\text { R:AGGAAACCCCACCG } \\
\text { F:CACTGCTCGTTGGC }\end{array}$ & 245 & $\begin{array}{l}(\mathrm{CACC} \\
\mathrm{AA}) 8\end{array}$ & 8.00 & 2.38 & 0.362 & 0.580 & -0.101 & 0.549 & 0.010 & -0.039 \\
\hline Average & & & & & 4.44 & 2.68 & 0.499 & 0.566 & 0.103 & 0.512 & 0.286 & \\
\hline
\end{tabular}

\subsection{Sibship assignment of progeny from a single cone}

Genotypes of 108 progeny seedlings from 15 cones were evaluated with nine SSR locus (null allele frequencies $<0.05$ ). The individuals from full-sibs family were analyzed with COLONY program (Table 2). COLONY implementing full-pedigree likelihood methods infers sibship among individuals (Jones and Wang, 2010). The individuals of non-full sibs from a cone were derived from different pollen donors. The number of progeny of a cone was from 4 to 13 , the average amount of which was 7.2 , and the number of conjectural pollen donors per cone was 3 to 7 . It could be 67 pollen donors for 15 cones and the average amount of pollen donors for a cone was 4.5 . 
Tree Genetics and Molecular Breeding 2020, Vol.10, No.5, 1-7

http://genbreedpublisher.com/index.php/tgmb

Table 2 Number of full-sib progeny and male parent from single Chinese fir cone

\begin{tabular}{|c|c|c|c|c|c|c|c|c|c|c|c|c|c|c|c|}
\hline \multirow[t]{2}{*}{ Full-sib family number } & \multicolumn{15}{|c|}{ Cone number } \\
\hline & 1 & 2 & 3 & 4 & 5 & 6 & 7 & 8 & 9 & 10 & 11 & 12 & 13 & 14 & 15 \\
\hline 1 & 1,3 & 1,9 & 1,2 & $1,5,6,10$ & $1,3,5,9$ & 1,9 & 1,5 & 1,3 & 1 & 1,5 & 1,2 & $1,4,5$ & 1 & $1,4,6$ & 1 \\
\hline 2 & 2,4 & $2,11,13$ & 3 & $2,3,7$ & 2 & 2,5 & 2 & 2 & 2 & 2 & 3 & 2 & 2 & 2,9 & 2,6 \\
\hline 3 & 5 & 3,4 & 4 & 4 & 4 & $3,4,10$ & 3,8 & 4 & 3,4 & 3 & 4 & 3 & 3,5 & 3,8 & 3 \\
\hline 4 & 6 & 5,10 & & 8,9 & 6 & 6,8 & 4,6 & 5 & & 4 & & & 4 & 5 & 4 \\
\hline 5 & 7 & 6 & & & 7 & 7 & 7 & & & 6,7 & & & & 7,10 & 5 \\
\hline 6 & & 7,12 & & & 8,10 & & & & & & & & & & \\
\hline 7 & & 8 & & & & & & & & & & & & & \\
\hline Number of progeny & 7 & 13 & 4 & 10 & 10 & 10 & 8 & 5 & 4 & 7 & 4 & 5 & 5 & 10 & 6 \\
\hline $\begin{array}{l}\text { Conjectural number of pollen } \\
\text { donors }\end{array}$ & 5 & 7 & 3 & 4 & 6 & 5 & 5 & 4 & 3 & 5 & 3 & 3 & 4 & 5 & 5 \\
\hline
\end{tabular}

\section{Discussion}

Trinucleotide repeats were the most abundant repeats in both EST-SSR and SSR from transcription factor unigene of Chinese fir (Wen et al., 2015; Li et al., 2019). The AT/AT and AAG/CTT repeats were predominant in din- and trinucleotide repeats of EST-SSR of Chinese fir (Wen et al., 2015). The AG/CT and AGC/GCT repeats were predominant in those of SSR from transcription factor unigene of Chinese fir (Xu et al., 2014; Li et al., 2019). This indicates that there are differences in the distribution of SSR motifs in the transcribed and non-transcribed regions of the Chinese fir genome. SLAF-SSR markers occurred a lot of stutter bands may be because these markers existed mainly in non-transcribed regions of the genome and flanking sequence of the markers were not conserved (Angers et al., 1997; Grimaldi et al., 1997). Although SLAF-SSR may be obtained more alleles per locus than EST-SSR, the locus with low null allele frequencies were all in the category of EST-SSR. It indicated that EST-SSR had a lower frequency of null alleles than genomic SSR (Rungis et al., 2004; Ellis et al., 2007). Sibship assignment by the program have been conducted in forest trees (Lalitha, 2000; Litkowiec et al., 2018). This is the first time to exposit that there are multiple pollinators for single cone in gymnosperm.

\section{Materials and Methods}

\subsection{Material collection and DNA extraction}

Fresh needles of 48 Chinese fir clones were collected in a clonal seed orchard located at Xishan Forest Farm, Rongan County, Guangxi Province, China as experimental materials. The clonal seed orchard was established with plus trees collected from Guangxi, Guangdong, Hunan, Guizhou, Fujian, Zhejiang. Twelve clones were randomly selected from 48 clones for SSR primer validity test. The polymorphism and null allele frequencies was assessed with 48 clones.

Fifteen Chinese fir clones were randomly selected from seed orchard. One cone was picked and numbered from each Chinese fir clones. The seeds were separated according to the clone number and cultured for germination. The seeds of each cone were wrapped in gauze and labeled. After sterilizing with $0.5 \%$ potassium permanganate solution for $25 \mathrm{~min}$, rinsing with distilled water for $3 \sim 5$ times, then soaking in water for 24 hours, and seeds were put on the pad with the infiltrated cotton wool in germination boxes. Germination boxes were put in constant temperature incubator at $25^{\circ} \mathrm{C}$. When the seedlings grew to about $10 \mathrm{~cm}$ high, the whole seedlings were placed in a $2 \mathrm{~mL}$ centrifuge tube and stored in an ultra-low temperature freezer at $-80^{\circ} \mathrm{C}$. A total of 108 seedlings were germinated, in which SSR loci were detected for full sibling group analysis. The total genomic DNA of each experimental material was extracted using an Ezup Column plant Genomic DNA Kit (Sangon Biotech, China) according to the instructions. The DNA extraction quality was measured by $1 \%$ agarose gel electrophoresis, and the DNA concentration was measured using a Nanodrop 2000 Spectrophotometer (Thermo Scientific). 


\subsection{SSR loci development and primer design}

One Chinese fir clone was randomly selected from each of six provinces for specific-locus amplified fragment sequencing (SLAF-seq). SLAF library construction were achieved as described (Wang et al., 2018). The SSR sites were searched using the MISA program (Beier et al., 2017) with SLAF-seq data. SSR containing di-, tri-, tetra-, penta-, or hexanucleotide units repeated at least $6,5,4,3$ or 3 times, respectively, were selected. The SSR markers were designed according to the SLAF-seq data and the transcriptome sequencing data (unpublished) with primer 5 software (Lalitha, 2000). The primers were commissioned by Sangon Biotech (China).

\subsection{Primer screening and SSR typing}

PCR reactions were employed in a total volume of $20 \mu \mathrm{L}$ contained with $1.0 \mu \mathrm{L}$ (about $50 \mathrm{ng}$ ) genomic DNA, $1.0 \mu \mathrm{L}$ forward primer $(10 \mu \mathrm{M}), 1.0 \mu \mathrm{L}$ reverse primer $(10 \mu \mathrm{M}), 1.6 \mu \mathrm{dNTP}$ Mixture (dATP, dTTP, dCTP, dGTP, each at $2.5 \mathrm{mM}), 2.0 \mu \mathrm{L}$ PCR Buffer ( $\mathrm{Mg}^{2+}$ plus), $0.1 \mu \mathrm{L}$ Taq $(5 \mathrm{U} / \mathrm{uL})$, supplemented with $20 \mu \mathrm{L}$ with $\mathrm{ddH}_{2} \mathrm{O}$. The PCR kit was purchased from Takara (Dalian, China). The following protocol was applied: initial denaturation at $95^{\circ} \mathrm{C}$ for 5 min followed by 35 cycles of $30 \mathrm{~s}$ of $95^{\circ} \mathrm{C}, 56^{\circ} \mathrm{C}$ for $30 \mathrm{~s}$, and extension at $72^{\circ} \mathrm{C}$ for $30 \mathrm{~s}$ followed by $10 \mathrm{~min}$. The PCR amplification products were detected by silver staining after $8 \%$ non-denaturing polyacrylamide gel electrophoresis.

\subsection{Statistical analysis}

According to the molecular weight, from large to low one, the alleles was recorded in alphabetical order. Allele sizes were estimated by comparison to an M13 sequence ladder. The observed number of alleles per locus $\left(N_{\mathrm{A}}\right)$, the effective number of alleles $\left(N_{\mathrm{E}}\right)$, Shannon Index Shannon's Information index $(I)$, observed heterozygosity observed heterozygosity $\left(H_{\mathrm{o}}\right)$, expected heterozygosity $\left(H_{\mathrm{E}}\right)$, Inbreeding among individuals within subpopulations ( $F$ is), Significant level for deviations from Hardy-Weinberg equilibrium ( $P$-Value) was calculated using POPGENE version 1.32 (Yeh et al., 1999). Polymorphism information content (PIC), the frequency of null alleles ( $F$-Null) were calculated using the computer program CERVUS (Kalinowski et al., 2007). Sibship identification was performed employing COLONY (Jones and Wang, 2010).

\section{Authors' contributions}

LKP carried out the experimental research, the data analysis, and drafted the manuscript. CSC participated in the experimental research and the data analysis. DLM participated in the data analysis. LJ and CDX participated in the experimental design. HKY was in charge of the project, guided experiment design and draft revision. All authors read and approved the final manuscript.

\section{Acknowledgments}

The authors would like to thank Professor Siming Gan from Research Institute of Tropical Forestry of Chinese Academy of Forestry for technical assistance. This work was financially supported by Department of Science and Technology of Guangxi Zhuang Autonomous Region, China (GK AA17204087-2), (GK AB1638005) and the Department of Human Resources and Social Security of Guangxi Zhuang Autonomous Region, China (GuiCaiSheHan[2018]112) and the Fundamental Research Funds for Guangxi Forestry Research Institute, China (NO.LK201805).

\section{References}

Angers B., Bernatchez L., 1997, Complex evolution of a salmonid microsatellite locus and its consequences in inferring allelic divergence from size information, Molecular Biology and Evolution, 14:230-238 https://doi.org/10.1093/oxfordjournals.molbev.a025759

Beier S., Thiel T., Münch T., Scholz U., Mascher M., 2017, MISA-web:a web server for microsatellite prediction, Bioinformatics, 33(16):2583-2585 https://doi:10.1093/bioinformatics/btx198

Dong L.M., Zhang S.G., Sun X.M., 2018, Application of Pedigree Reconstruction in Open-pollinated Progeny Testing of Japanese Larch, Scientia Silvae Sinicae, 31(1):27-35 http://doi:10.13275/j.cnki.lykxyj.2018.01.003

Dong S.R., Kong J., Zhang T.S., Meng X.H., Wang R.C., 2006, Parentage determination of Chinese shrimp (Fenneropenaeus chinensis) based on microsatellite DNA markers, Aquaculture, 258(1):283-288 https://doi.org/10.1016/j.aquaculture.2006.04.044 
Ellis J.R., Burke J.M., 2007, EST-SSRs as a resource for population genetic analyses, Heredity, 99:125-132 https://doi.org/10.1038/sj.hdy.6801001

Frankham R., Ballou J., Briscoe D., 2010, Introduction to Conservation Genetics, Cambridge University Press, Cambridge, pp260-308 https://doi.org/10.1017/CBO9780511808999

Gong W.L., Ma L., Gong P., Liu X.Q., Wang Z., Zhao G.Q., 2019, Development and application of EST-SSRs markers for analysis of genetic diversity in erect milkvetch (Astragalus adsurgens Pall), Molecular Biology Reports, 46(1): 1323-1326 https://doi/10.1007/s11033-018-4484-1

Grimaldi M.C., Crouau-Roy B., 1997, Microsatellite allelic homoplasy due to variable flanking sequences, Journal of Molecular Evolution, 44:336-340 https://doi.org/10.1007/PL00006151

Huang L.S., Song J.Y., Sun Y., Sun Y.Q., Gao Q., Jiao S.Q., Zhou S.S., Jin Y.Q., Yang X.L., Zhu J.J., Gao F.L., Yousry A., El-Kassaby., Mao J.F., 2018, Pollination dynamics in a Platycladus orientalis seed orchard as revealed by partial pedigree reconstruction, Canadian Journal of Forest Research, 48(8):952-957 https://doi.org/10.1139/cjfr-2018-0077

Jones O.R., Wang J., 2010, COLONY: a program for parentage and sibship inference from multilocus genotype data, Mol Ecol Resour, 10(3):551-555 https://doi.org/10.1111/j.1755-0998.20009.02787.x

Karam M.J., Aouad M., Roig A., Bile A., Dagherkharrat M.B., Klein E.K., Fady B., Lefevre F., 2019, Characterizing the genetic diversity of Atlas cedar and phylogeny of Mediterranean Cedrus species with a new multiplex of 16 SSR markers, Tree Genetics \& Genomes, 15(4):60 https://doi.org/10.1007/s11295-019-1366-1

Karaket T., Poompuang S., 2012, Cervus vs. colony for successful parentage and sibship determinations in freshwater prawn macrobrachium rosenbergii de man, Aquaculture, 324:307-311 https://doi.org/10.1016/j.aquaculture.2011.10.045

Kalinowski S.T., Taper M.L., Marshall T.C., 2007, Revising how the computer program CERVUS accommodates genotyping error increases success in paternity assignment, Molecular Ecology, 16:1099-1106 https://doi: 10.1111/j.1365-294X.2007.03089.x

Li K.P., Wei Z.C., Huang K.Y., Dong L.J., Huang H.F., Chen Q., Dai J., Tan W.J., 2017, Research on Variation Pattern of Wood Propertiesof Red-heart Chinese Fir Plus Trees, a Featured Provenance from Rongshui of Guangxi, Scientia Silvae Sinicae, 30(3): 424-429 http://en.cnki.com.cn/Article en/CJFDTotal-LYKX201703009.htm

Li K.P., Chen D.X., Huang K.Y., Chen X.M., Dai J., Chen Q., 2019, Distribution of Transcription Factor Unigene-derived Microsatellites (TFUMs) of Chinese Fir, Genomics and Applied Biology, 3:1199-1204 http://doi:10.13417/j.gab.038.001199

Litkowiec M., Lewandowski A., Wachowiak W., 2018, Genetic variation in Taxus baccata L.: a case study supporting Poland' s protection and restoration program, Forest ecology and management 409:148-160 https://doi.org/10.1016/j.foreco.2017.11.026

Leonarduzzi C., Piotti A., Spanu I., Vendramin G.G., 2016, Effective gene flow in a historically fragmented area at the southern edge of silver fir (Abies alba Mill.) distribution, Tree genetics \& genomes, 12(5):95 https://doi.org/10.1007/s11295-016-1053-4

Lalitha S., 2000, Primer premier 5, Biotech Software \& Internet Report: The Computer Software Journal for Scient, 1(6): 270-272 https://doi.org/10.1089/152791600459894

Rungis D., Bérubé Y., Zhang J., Ralph S.G., Ritland C., Ellis B.E., Douglas C.J., Bohlmann J., Ritland K., 2004, Robust simple sequence repeat markers for spruce (Picea spp.) from expressed sequence tags, Theoretical and Applied Genetics, 109:1283-1294 https://doi.org/10.1007/s00122-004-1742-5

Sonah H., Deshmukh R., Sharma A., Singh V., Gupta D.K., Gacche R.N., Rana J.C., Singh N.K., Sharma T.R., 2011, Genome-wide distribution and organization of microsatellites in plants: an insight into marker development in Brachypodium, PLoS ONE, 6(6): e21298 https://doi.org/10.1016/j.bse.2016.05.023

Selkoe K.A., Toonen R.J., 2006, Microsatellites for ecologists: a practical guide to using and ev-aluating microsatellite markers, Ecology Letters, 9:615-629 https://onlinelibrary.wiley.com/doi/abs/10.1111/j.1461-0248.2006.00889.x

Sahoo L., Meher P.K., Mahapatra K.D., Saha J.N., Jayasankar P., Das P., 2017, A molecular tool for parentage analysis in indian major carp, labeo rohita, (hamilton, 1822), Aquaculture International, 25(3):1159-1166 https://doi.org/10.1007/s10499-016-0104-Z

Sun X.W., Liu D.Y., Zhang X.F., Li W.B., Liu H., Hong W.G., Jiang C.B., Guan N., Ma C.X., Zeng H.P., Xu C.H., Song J., Huang L., Wang C.M., Shi J.J., Wang R., Zheng X.H., Lu C.Y., Wang X.W., Zheng H.K., 2013, SLAF-seq: an efficient method of large-scale De novo SNP discovery and genotyping using high-throughput sequencing, PLoS ONE, 8(3):e58700 https://www.ncbi.nlm.nih.gov/pmc/articles/PMC3602454/ doi: 10.1371/journal.pone.0058700 
Tree Genetics and Molecular Breeding 2020, Vol.10, No.5, 1-7 http://genbreedpublisher.com/index.php/tgmb

Torokeldiev N., Ziehe M., Gailing O., Finkeldey R., 2019, Genetic diversity and structure of natural Juglans regia L. populations in the southern Kyrgyz Republic revealed by nuclear SSR and EST-SSR markers, Tree Genetics \& Genomes, 15(1):5 https://doi.org/10.1007/s11295-018-1311-8

Wang X., Yang S., Chen Y.D., Zhang S.M., Zhao Q.S., Li M., Gao Y.L., Yang L., Bennetzen J.L., 2018, Comparative genome-wide characterization leading to simple sequence repeat marker development for Nicotiana, BMC genomics, 19(1):500 https://doi.org/10.1186/s12864-018-4878-4

Wen Y.F., Han W.J., Zhou H., Xu G.B., 2015, SSR Mining and Development of EST-SSR Markers for Cunninghamia lanceolata Based on Transcriptome Sequences, Scientia Silvae Sinicae, 51(11):40-49 http://doi:10.11707/j.1001-7488.20151106

Xiao J., Zhao J., Liu M.J., Liu P., Dai L., Zhao Z.H., 2015, Genome-wide characterization of simple sequence repeat (SSR) loci in Chinese jujube and jujube SSR primer transferability, PLoS ONE, 10(5):e0127812 https://PLOS ONE/doi:10.1371/journal.pone.0127812 May 22, 2015 4/13

Zurn J., Carter K., Yin M.H., Worthington M., Clark J.R., Finn C., Bassil N., 2018, Validating blackberry seedling pedigrees and developing an improved multiplexed microsatellite fingerprinting set, Journal of the American Society for Horticultural Science, 143(5):381-390 https://doi.org/ 10.21273/JASHS04474-18 